\title{
Studies on Coconut Shell Powder and Crysnanoclay Incorporated Acrylonitrile-Butadiene Rubber/ Styrene Butadiene Rubber Green Nanocomposites
}

\author{
Shahryar Pashaei, ${ }^{1}$ Soleyman Hosseinzadeh, ${ }^{2}$ Akheel Ahmed Syed ${ }^{3}$ \\ ${ }^{1}$ Department of Chemistry, Payame Noor University, Tehran, I.R of Iran \\ ${ }^{2}$ Department of Chemical Engineering, Payame Noor University, Tehran, I.R of Iran \\ ${ }^{3}$ Department of Studies in Chemistry, University of Mysore, Mysore 570 006, India
}

\begin{abstract}
The development of commercially viable "green products" based on natural resources for both matrices and reinforcements for a wide range of applications is on the rise. This effort includes new pathways to produce natural polymers with better mechanical properties and thermal stability using nanotechnology and use of naturally occurring fillers such as lignocellulosic and hemicellulose to make biodegradable rubber composites. The blends of acrylonitrile butadiene rubber (NBR) and styrene butadiene rubber (SBR) with coconut shell powder (CSP) have been prepared by using a compounding technique in presence of different amounts of crysnanoclay (CN). The effect of $\mathrm{CN}$ loading on tensile properties, thermal properties, swelling behavior, and water uptake behavior were studied. Significant improvement of Young's modulus and tensile strength was observed as a result of addition of nanoclay to the rubber matrix especially at $10 \mathrm{wt} \%$ loading. Presence of CSP resulted in ahigher in water sorption but after incorporation of $\mathrm{CN}$ the water sorption tended to decrease. Thermal characteristics were performed using thermogravimetric analysis (TGA). TGA thermograms indicated that incorporation of CSP filler decreases the thermal stability of nanocomposites. The dispersion of CSP and $\mathrm{CN}$ in rubber matrix was analyzed from scanning electron microscopy. POLYM. COMPOS., 38:727-735, 2017. (C) 2015 Society of Plastics Engineers
\end{abstract}

\section{INTRODUCTION}

In recent years there has been an extensive research work on development of newer materials with high performance at affordable costs. With growing environmental awareness, this search has particularly focused on eco-

Correspondence to: S. Hosseinzadeh; e-mail: hosseinzadeh65@gmail. com

DOI 10.1002/pc.23632

Published online in Wiley Online Library (wileyonlinelibrary.com).

(C) 2015 Society of Plastics Engineers friendly materials, with terms such as "renewable", "recyclable", "sustainable", and "triggered biodegradable" becoming buzzwords. This underscores the emergence of a new type of materials, a change from nonrenewable, but difficult to degrade or nondegradable, to renewable and easily degradable materials. The development or selection of a material to meet the desired structural and design requirements calls for a compromise between conflicting objectives. This can be overcome by resorting to multi objective optimization in material design and selection. Composite materials, which are prepared using natural or synthetic reinforcements and a variety of matrix materials, are included in this philosophy.

Clay and clay minerals, such as sodium montmorillonite, saponite, hectorite, bentonite, etc., have been widely used as natural fillers in making the nanocomposites. Not only has the development of polymer-claynanocomposites gained a lot of interest in recent years, but developments in rubber-clay nanocomposites have also captured the eyes of many researchers. The main reasons for adding clay fillers to rubber are to enhance thermo mechanical properties and to make the final products less expensive. The ability of layered silicates to separate in to individual layers with a very high aspect ratio (high length-to-width ratio) and to undergo ion-exchange reactions with inorganic or organic cations are general concerns in making rubber-clay nanocomposites.

Regarding the phase specific distribution of clay in heterogeneous polymer blends several works showed that clay preferentially resides in that blend phase having the better affinity to clay $[1,2]$. If clay shows the same affinity to both blend phases it concentrates dominantly at the interphase [3]. Several studies of polymer blend/clay systems indicated that a compatibilizing effect of clay in heterogeneous blends exists $[4,5]$. The droplet size of the dispersed phase in NBR/styrene butadiene rubber (SBR) [6]. The present research work is aimed at studying the 
TABLE 1. Typical formulations and sample code for (NBR /SBR)/CSP/CN nanocomposites.

\begin{tabular}{|c|c|c|c|c|c|}
\hline \multirow[b]{2}{*}{ Formulation (phr) } & \multicolumn{5}{|c|}{ Sample code } \\
\hline & SN1 & SN2 & SN3 & SN4 & SN5 \\
\hline NBR + SBR $(50 / 50)$ & 100 & 100 & 100 & 100 & 100 \\
\hline Carbon black & 40 & 40 & 40 & 40 & 40 \\
\hline Nanoclay & 0 & 0 & 2.5 & 5 & 10 \\
\hline Coconut shell powder & 0 & 5 & 5 & 5 & 5 \\
\hline Sulphur & 1.5 & 1.5 & 1.5 & 1.5 & 1.5 \\
\hline MBTS & 1.5 & 1.5 & 1.5 & 1.5 & 1.5 \\
\hline ZMDC & 0.5 & 0.5 & 0.5 & 0.5 & 0.5 \\
\hline Zinc oxide & 5 & 5 & 5 & 5 & 5 \\
\hline Stearic acid & 1.0 & 1.0 & 1.0 & 1.0 & 1.0 \\
\hline Anti-oxidant & 1.5 & 1.5 & 1.5 & 1.5 & 1.5 \\
\hline
\end{tabular}

effect of coconut shell powder (CSP) and crysnanoclay (CN) networking on the mechanical, thermal, swelling, and morphological behaviors of (NBR/SBR)/GP/CN nanocomposites to compare them with blend matrix.

\section{EXPERIMENTAL}

\section{Materials}

The elastomer used for preparing nanocomposites was SBR Kosyn 1502; styrene content is $23 \mathrm{wt} \%$; (random copolymer) and specific gravity is 0.945 was obtained from Kumpho Petrochemicals, Korea. The NBR - JSR N230 SL (acrylonitrile content $\sim 32 \%$ with specific gravity $=1.17 \pm 0.005$ ) was obtained from JSR, Japan. CSP is similar to hard woods in chemical composition though the lignin content is higher (35-45\%) and the cellulose content is lower (23-43\%). The CSP (particle size: $30-40$ $\mu \mathrm{m})$ was obtained from local industry. The Crysnano 1030 is a natural montmorillonite mineral modified with quaternary ammonium salt. The typical properties of crysnano 1030 are; $d$-value-19 $\mathrm{nm}$ and specific gravity1.97 at $25^{\circ} \mathrm{C}$. It was obtained from Talegaon Dabhade, Pune, India. The NBR/SBR blends were formulated with dibenzothiazole disulfide (MBTS), zine dimethyl dithiocarbamate (ZMDC), zinc oxide, stearic acid, sulfur, and carbon black (N330).

\section{Filler Preparation}

The CSP was thoroughly washed with water to remove sand and other foreign impurities adhere on filler surface, dried in sunlight, and ground to fine powder of it, particles size of $<240 \mu \mathrm{m}$. This fine powder was dried again in hot oven with air circulation for $12 \mathrm{~h}$ at $65^{\circ} \mathrm{C}$ and further used as filler.

\section{Preparation of Rubber/Nanocomposites}

The compounding formulation for the NBR and SBR blends with its various ingredients are mixed in a two roll mill at a friction ratio of 1:1.25 following standard mixing sequence for $1 \mathrm{~h}$ at room temperature. The compounded blends were vulcanized in an electrically heated, auto-controlled hydraulic press at $170^{\circ} \mathrm{C}$ in $20 \mathrm{~min}$ and pressure $4 \mathrm{MPa}$. The dumb-bell specimens were prepared using a die cutter. Compounding formulations of the prepared (NBR/SBR)/CSP/CN nanocomposites along with sample code are given in Table 1.

\section{Mechanical Properties}

Dumb-bell shaped samples were cut from the molded sheets and the tensile testing procedure was done according to ISO 37. The tensile test was performed at a crosshead speed of $500 \mathrm{~mm} / \mathrm{min}$ using an Instron 3366. The hardness measurements of the samples were done according to ISO 48 using a Wallace dead load instrument with a hardness range from 30 to 85 IRHD (international rubber hardness degree).

\section{Compression Set Measurement}

Compression set test (ASTM D395) [7] was performed on standard test specimen of cylindrical shape of $25 \pm 0.1 \mathrm{~mm}$ diameter and $12 \pm 0.5 \mathrm{~mm}$ thickness, vulcanized by compression mold. The test specimen shall be placed between the plates of the compression device with the spacers on each side of it, allowing sufficient clearance for bulging of the rubber when compressed. The bolts shall be tightened so that the plates are drawn together uniformly until they are in contact with the spacers. The percentage of the compression employed shall be $25 \%$ of the original thickness. Then the assembled compression device shall be placed in oven at $70^{\circ} \mathrm{C}$ for $22 \mathrm{~h}$. After completion of the assembly and remain in dry air circulated oven for specific period at the test temperature, the device shall be taken out from the oven and the test specimen removed immediately and allowed to cool for $30 \mathrm{~min}$, after this the final thickness shall be measured by an electronic digital caliber with $0.01 \mathrm{~mm}$ accuracy. The compression set is defined as 


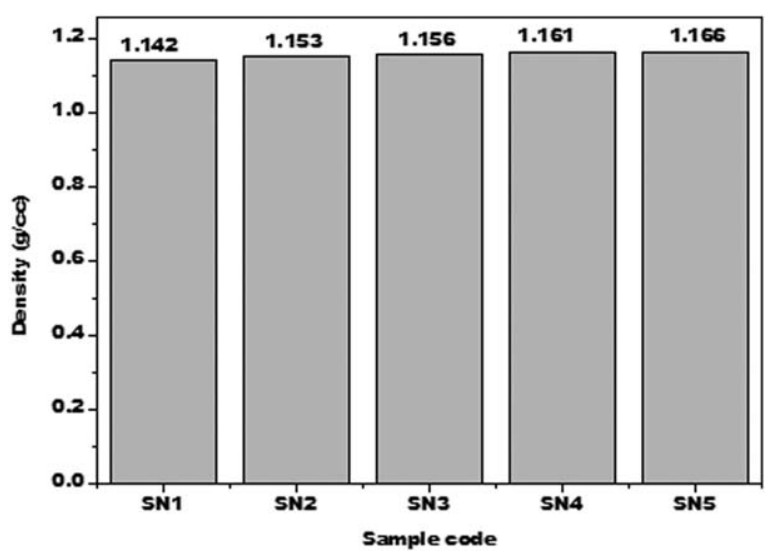

FIG. 1. The bar chart of density as a function of CSP and nanofiller content for (NBR/SBR)/CSP/CN nanocomposites.

$$
C \%=\frac{t_{0}-t_{1}}{t_{0}-t_{1}} \times 100
$$

where $t_{0}$ is the original thickness of the sample; $t_{1}$ is the thickness of the sample after removed from the clamp; and $t_{\mathrm{s}}$ is the thickness of the spacer bar used.

\section{Swelling Behavior}

Procedure to measure percent swelling of composites in organic solvents is briefly explained as follows: known weights $\left(w_{1}\right)$ of dried nanocomposites were immersed in different solvents until a state of equilibrium was attained at room temperature. When material swells, weight of the swollen material is noted $\left(w_{2}\right)$. The percentage of swelling was calculated by the relation [8]

$$
\text { Percentage swelling }=\frac{W_{2}-W_{1}}{W_{1}} \times 100
$$

\section{Fourier Transforms Infrared (FT-IR) Spectroscopy}

The FTIR spectra were obtained using Perkin-Elmer Spectrum and the attenuated total reflection (ATR) tech-

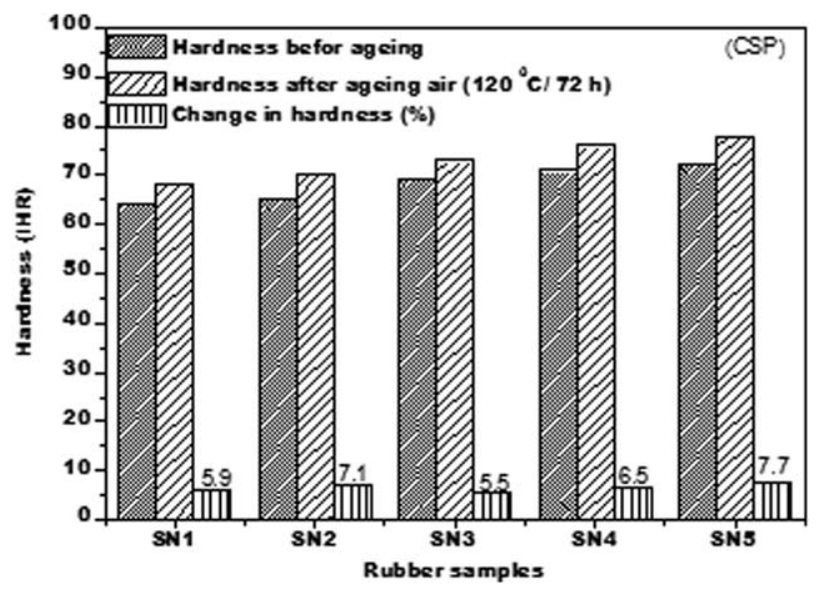

FIG. 2. Surface hardness results of NBR/SBR and its nanocomposites. nique was adopted. The selected spectrum resolution and the scanning range were 4 and $600-4000 \mathrm{~cm}^{-1}$, respectively.

\section{Termogravimetric Analysis}

The thermal stability of the NBR/SBR (50/50) and its nanocomposites have been evaluated using DuPont TGA instrument, USA with TGA-Q 50 module. The instrument was calibrated using pure calcium oxalate sample before analysis. About $6-8 \mathrm{mg}$ of sample was used for dynamic thermogravimetric analysis (TGA) scans at a heating rate of $20^{\circ} \mathrm{C} / \mathrm{min}$ in the temperature range of ambient to $700^{\circ} \mathrm{C}$ in nitrogen gas purge. The oxidation index (OI) was calculated based on the weight of carbonaceous char as related by the empirical equation [9]

$$
\mathrm{OI} \times 100=17.4 \times 0.4 \mathrm{CR}
$$

\section{Scanning Electron Microscopy (SEM)}

Scanning electron microscopy (VPFESEM), model Zeiss SUPRA 35VP was used to analyze the surface aspects concerning the quality of bonding and to detect the presence of micro-defects, if any. Samples were mounted on aluminium stubs and the surface sputter coated with a thin layer of gold, about $20 \mathrm{~mm}$ thick, prior to scanning to avoid electrostatic charging and poor resolution during examination.

\section{RESULTS AND DISCUSSION}

\section{Physico-Mechanical Properties}

The calculated tensile strength, tensile modulus at $100 \%$ elongation and at $200 \%$ elongation, elongation at break, surface hardness, and density for all the compounds are shown in Figs. 1-6. They showed the physico-mechanical properties before heat ageing, after heat aging, and percentage retained property such as tensile strength, elongation at break, Young's modulus (100\% elongation and 200\% elongation), and surface hardness for NBR/SBR/CSP/CN nanocomposites.

Density. The NBR/SBR had an average density of $1.142 \mathrm{~g} / \mathrm{cc}$. The calculated density values for all (NBR/ $\mathrm{SBR} / \mathrm{CSP} / \mathrm{CN}$ nanocomposites are given in Fig. 1. From the figure it can be noticed that, the density of the (NBR/ $\mathrm{SBR}) / \mathrm{CSP} / \mathrm{CN}$ nanocomposites increases as increase in crysnanoclay content as expected. This is because of increase in high dense clay filler in low dense NBR/SBR matrix.

Surface Hardness Before and After Heat Ageing. Figure 2 has been showed the surface hardness of the (NBR/ SBR)/CSP/CN nanocomposites. The graph showed that 


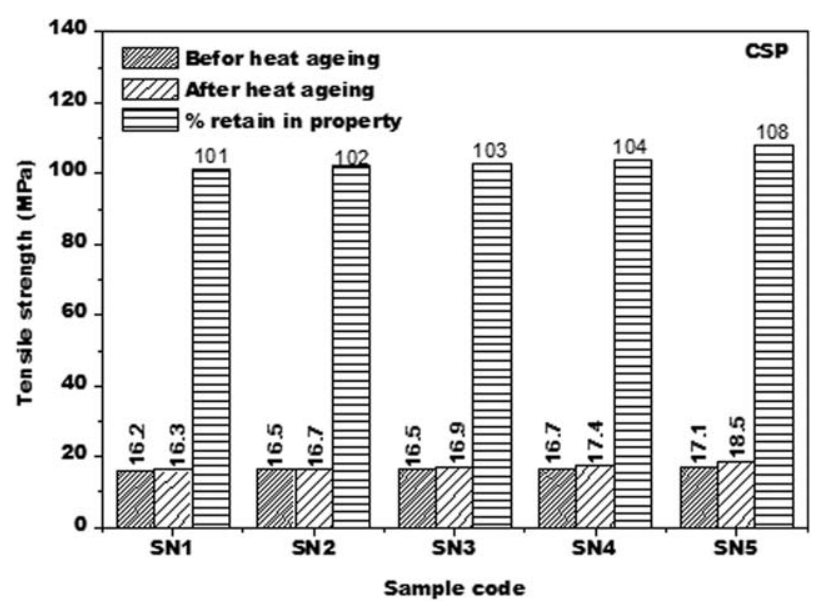

FIG. 3. Tensile strength of the NBR/SBR (50/50) blend and (NBR/ $\mathrm{SBR}) / \mathrm{CSP} / \mathrm{CN}$ nanocomposites.

hardness of (NBR/SBR)/CSP increases as a function of clay content in the following order: $\mathrm{SN} 5>\mathrm{SN} 4>$ SN3 $>$ SN2 $>$ SN1, as expected. Compared with before ageing and after aging in air $\left(120^{\circ} \mathrm{C} / 72 \mathrm{~h}\right)$ nanocomposites provide increments of $5.9 \%, 7.1 \%, 5.5 \%, 6.5 \%$, and $7.7 \%$ on the hardness values respectively. It is noticeable that the CSP and nanoclay behaves like a reinforcing agent in rubber matrix and enhances the surface hardness of the nanocomposites.

Tensile Behavior Before and After Heat Aging. The tensile strength before heat ageing, after heat ageing, and percent of retain property for rubber blend and its nanocomposites is addressed in Fig. 3. The tensile strength for green composite and nanocomposites are higher than NBR/SBR (50/50) blend (SN1). There is a slight increase in tensile strength with the incorporation of CSP and $\mathrm{CN}$, may be because of the good interfacial interaction between blend rubber and $\mathrm{CN}$ along with CSP. The value of tensile strength increased with increasing heat ageing because of crosslinking effect.

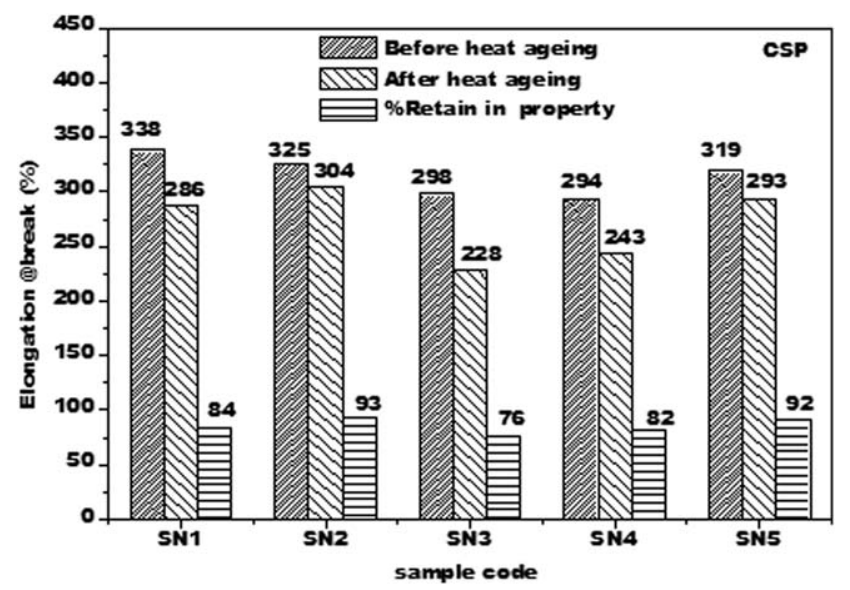

FIG. 4. Elongation at break values of the NBR/SBR (50/50) blend and (NBR/SBR)/CSP/CN nanocomposites.

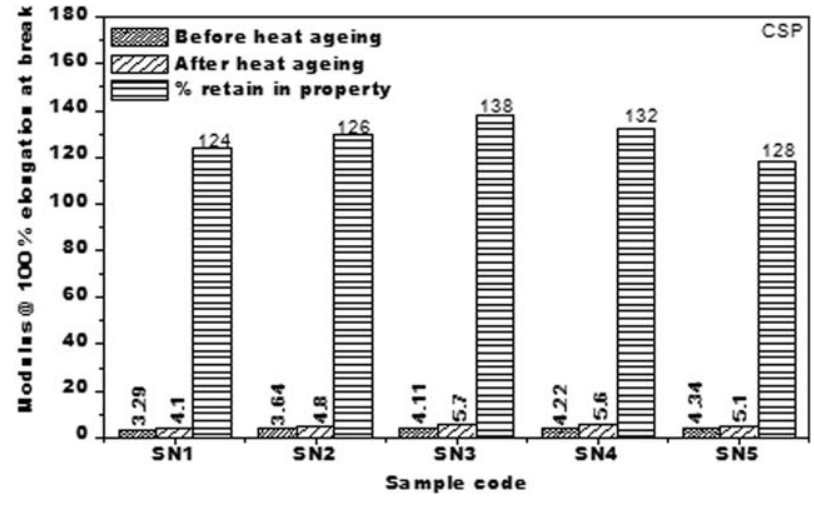

FIG. 5. Young's modulus at $100 \%$ elongation at break of the NBR/ SBR (50/50) blend and (NBR/SBR)/CSP/CN nanocomposites.

The (NBR/SBR)/GP/CN nanocomposites showed a noticeable reduction in percentage elongation at break (Fig. 4). The \% retain in elongation at break lies in the range 84-92. From Fig. 4 it was noticed that the elongation at break decreased after heat ageing because of increase in cross-linking density and lignocellulosic fillers have low elongation at break and restrict the polymer molecules flowing past one another.

Figures 5 and 6 showed significant increase in modulus at $100 \%$ and $200 \%$ elongation as a function of clay content as compared to rubber blend. The modulus at $100 \%$ and $200 \%$ elongation increased because the strong interaction between the crysnanoclay layers and rubber chains, which increased the constraint of the motion of the rubber chains. The percentage retain in property of nanocomposites increased after heat ageing because of increase in crosslink density of the composites. Figure 7 revealed that modulus at $200 \%$ elongation is higher than modulus at $100 \%$ elongation may be because of crosslinking effect. The tensile modulus is increased after incorporating nanoclay along with CSP into rubber matrix.

Compression Set Study. The compression set of the rubber compounds are shown in Fig. 8. Compression set is a measure of the ability of the rubber to retain their

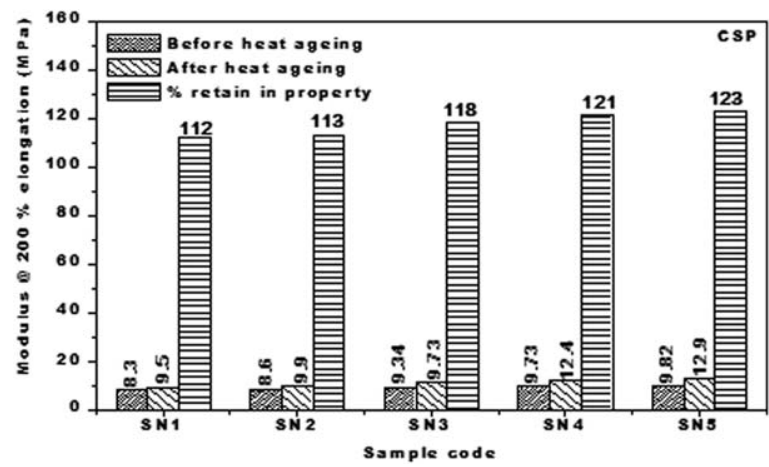

FIG. 6. Young's modulus at $200 \%$ elongation at break of the NBR/ SBR (50/50) blend and (NBR/SBR)/CSP/CN nanocomposites. 


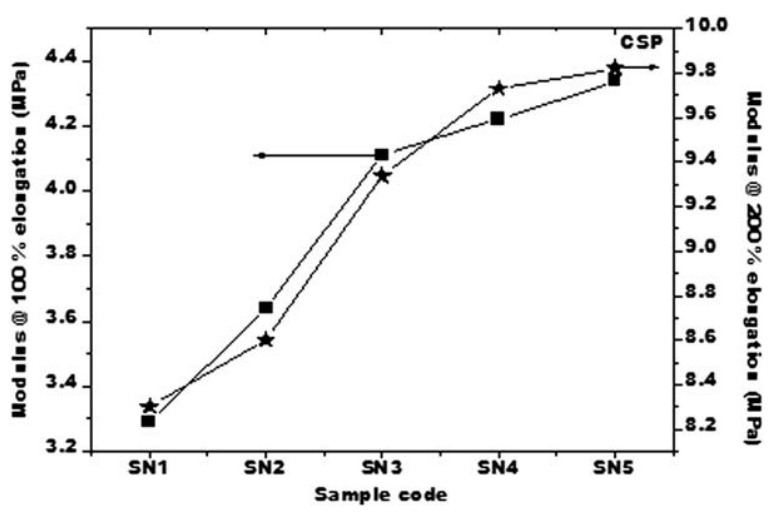

FIG. 7. Modulus at $100 \%$ elongation and modulus at $200 \%$ elongation for $(\mathrm{NBR} / \mathrm{SBR}) / \mathrm{CSP} / \mathrm{CN}$ nanocomposites as a function of clay content.

elastic properties after subjected to prolonged compression load at a constant strain under a specified set of conditions, and it is a permanent set of rubber compounds $[10,11]$. The SN5 have showed higher value in compression set because of the incorporation of crysnanoclaywith rubber blend. The rigid clay filler restricts the chain mobility of network of elastomer chain.

\section{FT-IR Spectral Analysis}

The IR spectra of the NBR/SBR blend and (NBR/ $\mathrm{SBR}$ )/CSP/CN nanocomposites are shown in Fig. 9. FTIR spectra indicates that, the peak at $3,730-3,400 \mathrm{~cm}^{-1}$ which may be because of the stretching peak of $-\mathrm{OH}$ bond of stearic acid, but it has been become board after incorporating CSP and $\mathrm{CN}$ because of overlapping of the $-\mathrm{OH}$ groups of lignin, cellulose and the $\mathrm{Si}-\mathrm{OH}$ groups band. The broad and strong band ranging from 3,000 to $3,600 \mathrm{~cm}^{-1}$ indicates the overlapping of $\mathrm{Si}-\mathrm{OH}$ (silanol) and $\mathrm{R}-\mathrm{OH}$ (hydroxyl) groups of CSP stretching vibrations. The peak visible at $2,913 \mathrm{~cm}^{-1}$ is because of the symmetric stretching of the $\mathrm{C}-\mathrm{H}$ band. The peaks observed at 2,922 and $2,851 \mathrm{~cm}^{-1}$ can be assigned to asymmetric and symmetric $-\mathrm{CH}_{2}$ groups. The peak at $2,325 \mathrm{~cm}^{-1}$ is because of the $\mathrm{C}-\mathrm{H}$ band of SBR and at $2,260-2,240 \mathrm{~cm}^{-1}$ is because of nitrile linkages of blend. The peak at $1,600 \mathrm{~cm}^{-1}$ is because of the $\mathrm{C}=\mathrm{C}$ band of butadiene in the system. The peak at $1,636 \mathrm{~cm}^{-1}$ corre-

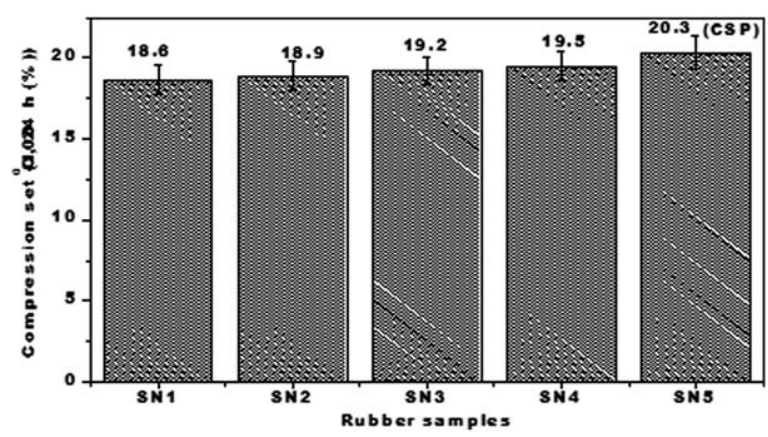

FIG. 8. Compression set study of (NBR/SBR)/CSP/CN nanocomposites.

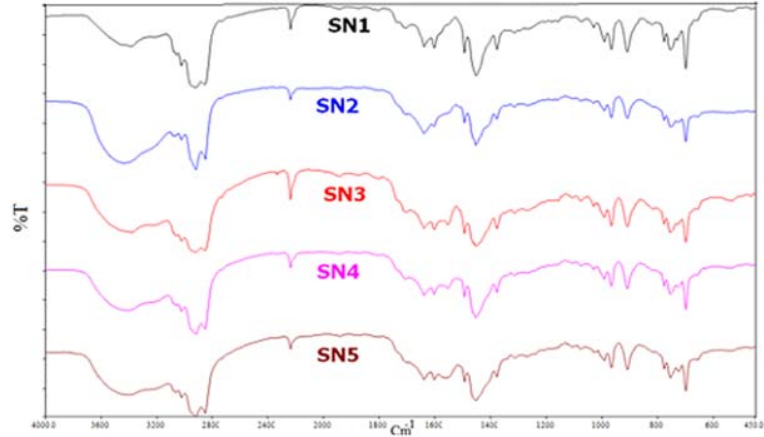

FIG. 9. FTIR spectra of NBR/SBR blend and its composites. [Color figure can be viewed at wileyonlinelibrary.com]

sponds to the $\mathrm{C}=\mathrm{C}$ stretching that can be attributed to the aromatic group and the peak at $1021 \mathrm{~cm}^{-1}$ is may be because of the styrene [12]. There is no peak at $1730 \mathrm{~cm}^{-1}(>\mathrm{C}=\mathrm{O}$ stretching peak), which indicated that the oxidation of main polymeric chain did not occurred at the time of rubber milling with the help of cracker cum mixing mill at high temperature. The wave numbers from 1400 to $1600 \mathrm{~cm}^{-1}$ are assigned to aromatic skeletal vibration.

\section{Water Absorption Behavior}

Water diffusion into the polymer depends upon the molecular and micro structural aspects such as polarity, the extent of crystallinity of matrix material and/or presence of other water attractive substances. Cellulose fibres are difficult to dissolve because of their high crystallinity, but they tend to absorb and retain the water in the inter fibrillar spaces. Water sorption of the prepared green composite and nanocomposites were measured at room temperature and the results are presented in Fig. 10. Adding CSP into rubber resulted in increasing water sorption of the nanocomposites because of the hydrophilic nature of cellulose and lignin. However, increasing the nanoclay loading from $2.5 \%$ to $10 \%$ resulted in a slight decrease in

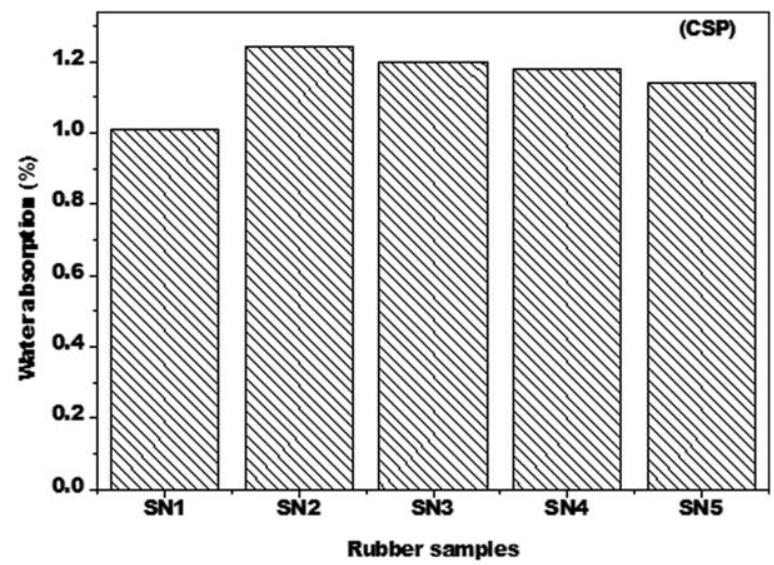

FIG. 10. Effect of CSP and $\mathrm{CN}$ on water absorption behavior of (NBR/SBR)/CSP/CN nanocomposites. 

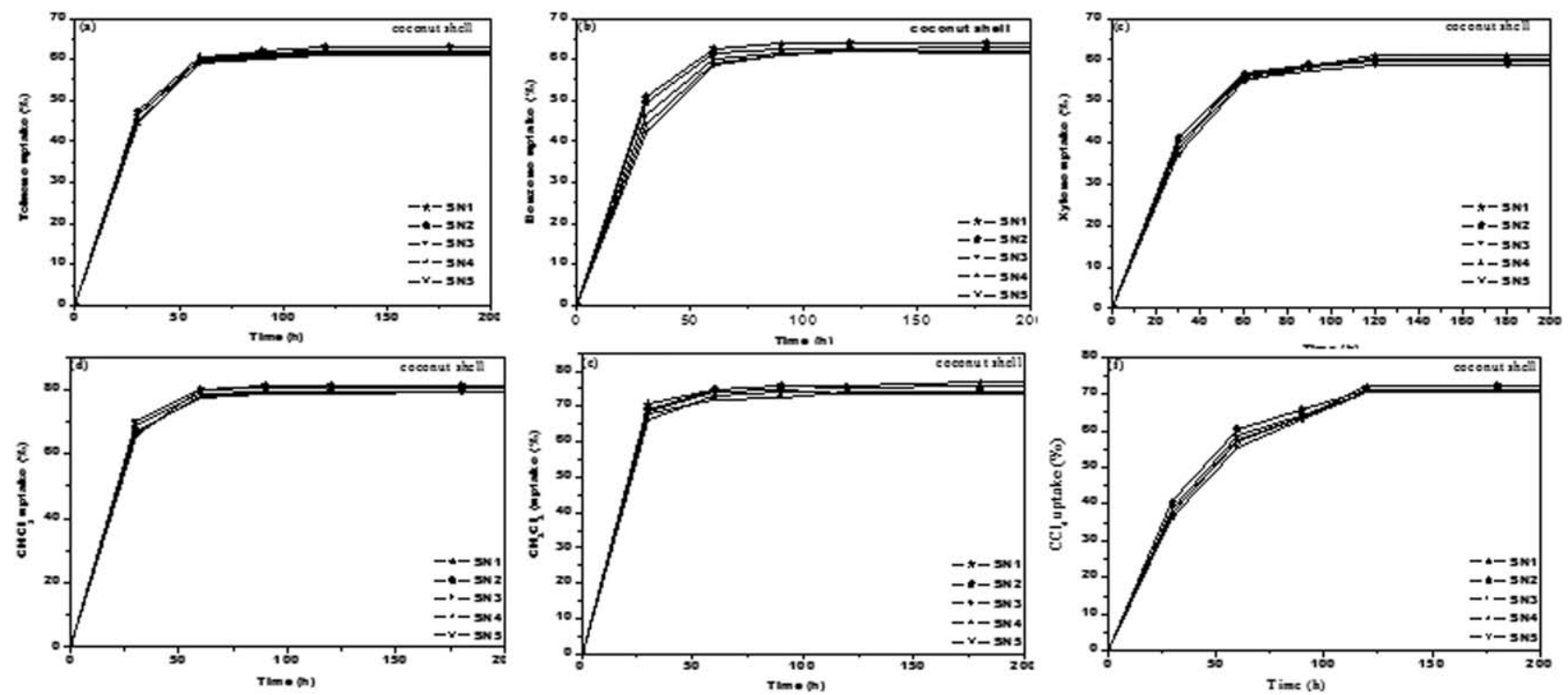

FIG. 11. Swelling behavior of (NBR/SBR)/GP/CN nanocomposites in organic solvents.

moisture sorption was noticed. Different interpretations may be proposed to explain this result.

The water diffusivity appears as an increasing function with respect to filler content. In such a case, the fillers favour the penetration of water into the specimen's interior, which should have a negative influence on durability. The interfacial zone can play a positive role during the water absorption process. Similar kind of results has been observed by Chow et al. [13] in the case of polyamide-6/polypropylene (PP) nanocomposites.

\section{Swelling Behavior of Nanocomposites}

To study the effect of CSP loading on the swelling behavior of (NBR/SBR)/CSP/CN nanocomposites, the

TABLE 2. Thermal degradation temperature range obtained from derivative TGA curves of (NBR/SBR)/CSP/CN nanocomposites.

\begin{tabular}{lllllr}
\hline & & \multicolumn{3}{c}{ Temperature $\left({ }^{\circ} \mathrm{C}\right) \pm 2$} & \\
\cline { 3 - 5 } Sample code & Step & $T_{0}$ & $T_{\mathrm{p}}$ & $T_{\mathrm{c}}$ & Weight loss (\%) \\
\hline SN1 & I & 232 & 312 & 348 & 6.5 \\
& II & 348 & 474 & 525 & 63.6 \\
SN2 & Ash & - & - & - & 29.9 \\
& I & 230 & 311 & 351 & 6.7 \\
& II & 351 & 474 & 532 & 63.2 \\
SN3 & Ash & - & - & - & 30.1 \\
& I & 227 & 312 & 351 & 7.3 \\
& II & 351 & 480 & 530 & 61.7 \\
SN4 & Ash & - & - & - & 31.0 \\
& I & 227 & 310 & 350 & 7.6 \\
\multirow{2}{*}{ SN5 } & II & 350 & 480 & 532 & 61.0 \\
& Ash & - & - & - & 31.4 \\
& I & 225 & 312 & 347 & 7.8 \\
& II & 347 & 480 & 537 & 59.4 \\
& Ash & - & - & - & 32.8 \\
\hline
\end{tabular}

samples were exposed to different aliphatic halogenated hydrocarbon $\left(\mathrm{CHCl}_{3}, \mathrm{CH}_{2} \mathrm{Cl}_{2}\right.$, and $\left.\mathrm{CCl}_{4}\right)$ and aromatic solvents (benzene, toluene and p-xylene). The obtained results of solvent uptake as a function of time are plotted in Fig. 11. From the figure it can be seen that, the NBR/ SBR swells to higher extent as compared to that of filled (NBR/SBR)/CSP/CN nanocomposites. It has also been found that the least solvent uptake was noticed for composites in p-xylene and maximum was in chloroform. However, NBR/SBR exhibited higher solvent uptake in chloroform. The order of swelling is as follows; chloroform $>$ dichloromethane $>$ carbon tetrachloride $>$ benzene $>$ toluene $>$ p-xylene.

The swellability depends on the polarity, solubility parameter, dielectric constant and molecular size of the solvents. Solvent absorption decreased with increasing nanoclay content (Fig. 11) because of good dispersion of nanoclay and the strong physical interactions between nanoclay and rubber matrix. The presence of nanodispersed $(\mathrm{CN})$ impermeable layers with excellent barrier properties decreased the rate of water transportation by lengthening the average diffusion path length in NBR/ SBR matrix [14].

\section{Thermogravimetric Analysis}

TGA has proved to be a suitable method to investigate the thermal stability of polymeric systems [15]. All the (NBR/SBR)/CSP/CN nanocomposites were stable upto $225^{\circ} \mathrm{C}$ (Table 2). The threshold decomposition temperature gives an indication of the highest processing temperature that can be adopted.

The TGA and DTG curves of NBR/SBR blend and (NBR/SBR)/CSP/CN nanocompositesare shown in Fig. 12. TGA thermograms of all nanocomposites are shown 

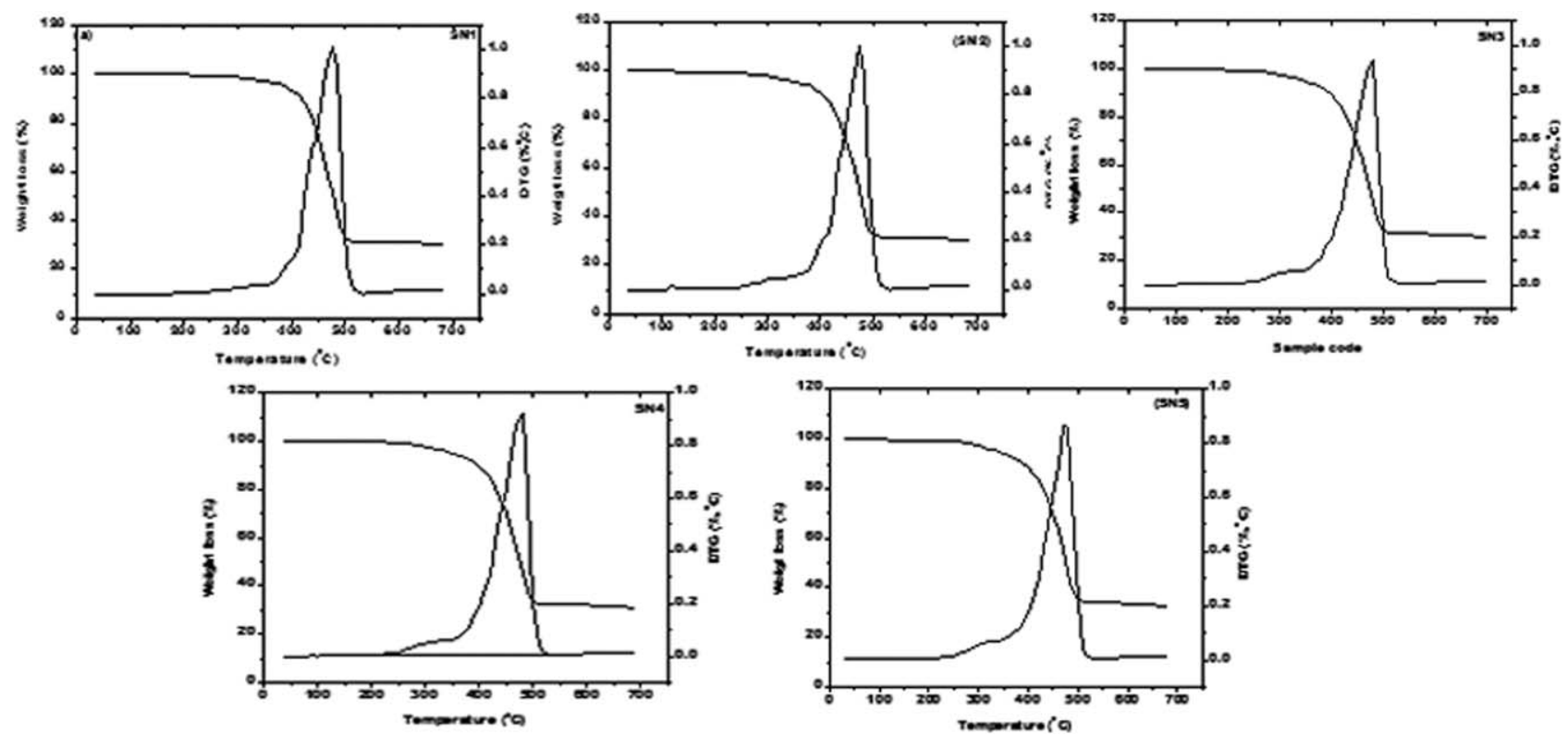

FIG. 12. TGA and derivative thermograms of, SN1, SN2, SN3, SN4 and SN5 nanocomposites.

in Fig. 13. TGA thermograms indicate that all composites have undergone two steps thermal degradation in the temperature range $240-355^{\circ} \mathrm{C}$ and $355-529^{\circ} \mathrm{C}$ for first and second steps respectively. The weight loss occurred in first step lies in the range $6.5-7.8 \%$ which is because of processing oil along with little amount of CSP and moisture content. The second step weight loss occurred in the temperature range $350-537^{\circ} \mathrm{C}$, with a weight loss of 59.4-63.6, which is because of depolymerisation of vulcanised rubber. Table 2 indicates that, ash content increases with increase in filler loading [16]. The ash content of the composites lies in the range 29.9-32.8\%, which is because of nanoclay and un-pyrolysed carbon black. This can be attributed to the synergistic effect of nanoclay and CSP present in the composite. The higher ash content was obtained in this study than expected theoretically, it can be attributed to TGA scans were recorded in presence of inert $\left(\mathrm{N}_{2}\right)$ gas purge.

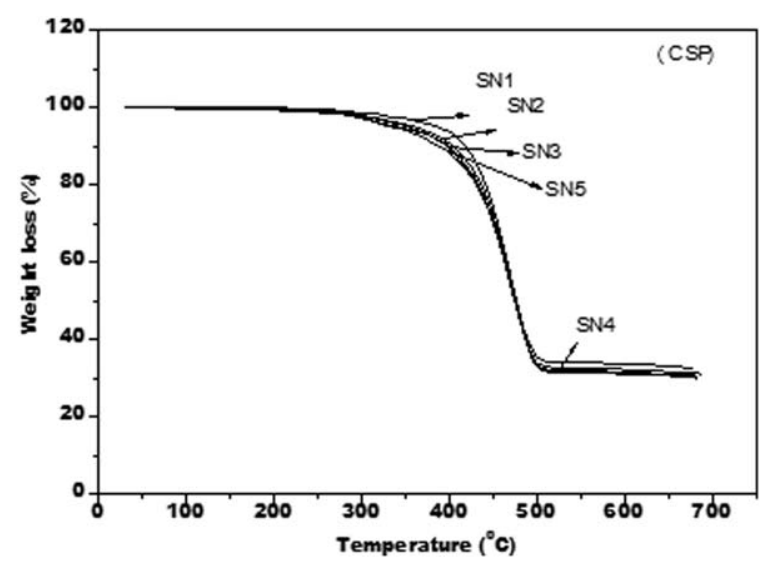

FIG. 13. TGA thermograms of NBR/SBR blend and their green hybrid composites.
From TGA thermograms, the measured $T_{0}, T_{10}, T_{20}$, $T_{30}, T_{50}$, and $T_{\max }$ were listed in Table 3. From Fig. 13 the values of onset $\left(T_{\mathrm{o}}\right)$ and degradation temperature $\left(T_{\mathrm{p}}\right)$ of rubber blend and (NBR/SBR)/CSP/CN nanocomposites were obtained (Table 3). The presence of nanoclay does not affect the thermal stability of the composites. For blend matrix the weight loss starts at $340^{\circ} \mathrm{C}$ which reduces slightly by the addition of CSP. Higher the values of oxidation index (OI), higher will be the thermal stability [17-19]. From Table 3 it was observed that the oxidation index values increases with increase in nanoclay content and it lies in the range 2.0-2.3. Annakutty reported that, the char yield is directly correlated to the potency of flame retardation [20]. From the aforesaid investigation, it can be concluded that the flame resistance of (NBR/SBR)/CSP/CN nanocomposites was slightly enhanced as the filler content increases.

\section{Dispersion of Fillers}

The dispersion of filler in polymer matrix is the deciding factor on performance of composites. According to the method described in the ISO standard [21] the dispergrader works with a light source at an angle of $30^{\circ}$, with respect to the observation surface and at a magnification of $\times 100$. A grey scale image was obtained (Fig. 14). The light dots are associated with filler and agglomerates whereas the dark background is associated with the rubber matrix. This image is transformed by numerical treatment into a black and white image. From Fig. 14, it can be noticed that SN1 has smooth surface, because it has no fillers. The green composite and nanocomposites were showed two-phase morphology that is one black color for rubber phase and second white color is for fillers phase. 
TABLE 3. Effect of coconut shell powder and crysnanoclay on thermal stability of (NBR/SBR)/CSP/CN nanocomposites.

\begin{tabular}{lllllll}
\hline & \multicolumn{7}{c}{ Temperature at different weight loss $\left( \pm 2^{\circ} \mathrm{C}\right)$} & $T_{\max }$ & Oxidation index $(\%)$ \\
\cline { 2 - 6 } Sample code & $T_{0}$ & $T_{10}$ & $T_{20}$ & $T_{50}$ & 685 & 2.0 \\
\hline SN1 & 340 & 410 & 440 & 475 & 685 & 2.0 \\
SN2 & 320 & 400 & 435 & 475 & 690 & 2.1 \\
SN3 & 315 & 400 & 435 & 475 & 690 & 2.2 \\
SN4 & 315 & 400 & 435 & 475 & 695 & 2.3 \\
SN5 & 310 & 402 & 430 & 475 & & \\
\hline
\end{tabular}

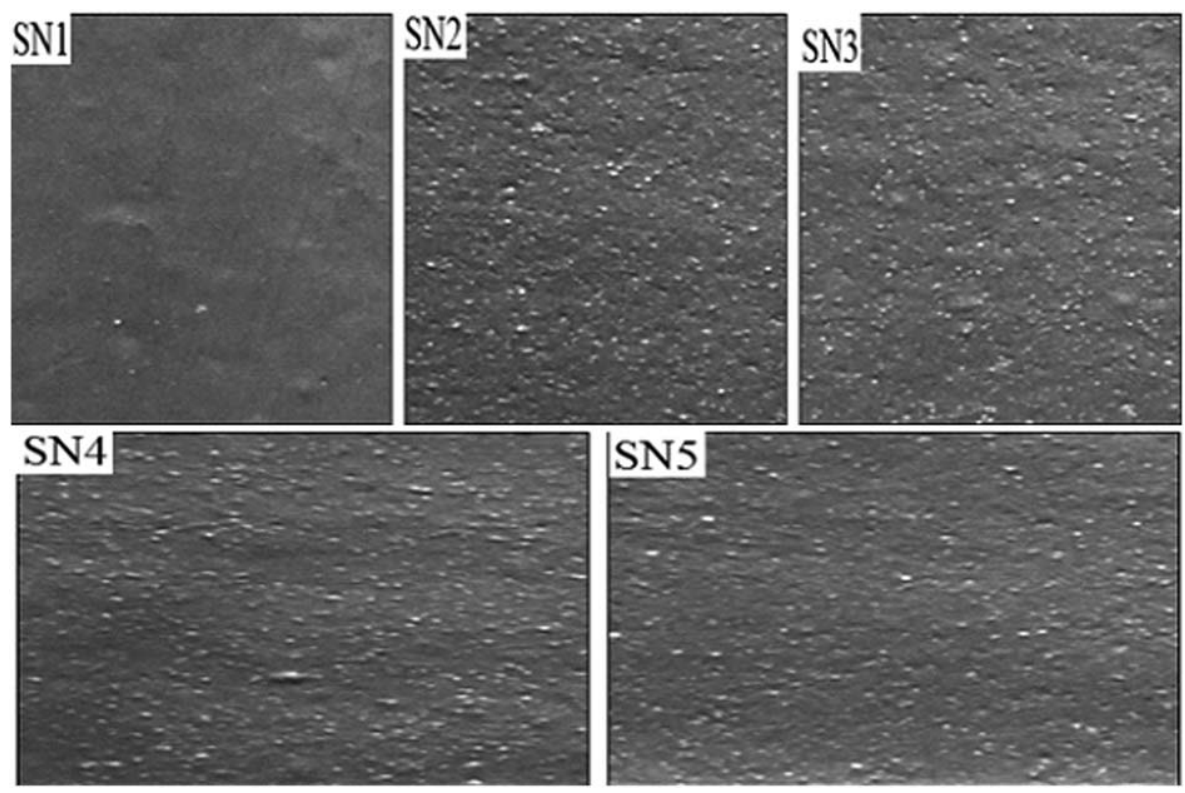

FIG. 14. Dispersion images of NBR/SBR and its composites.
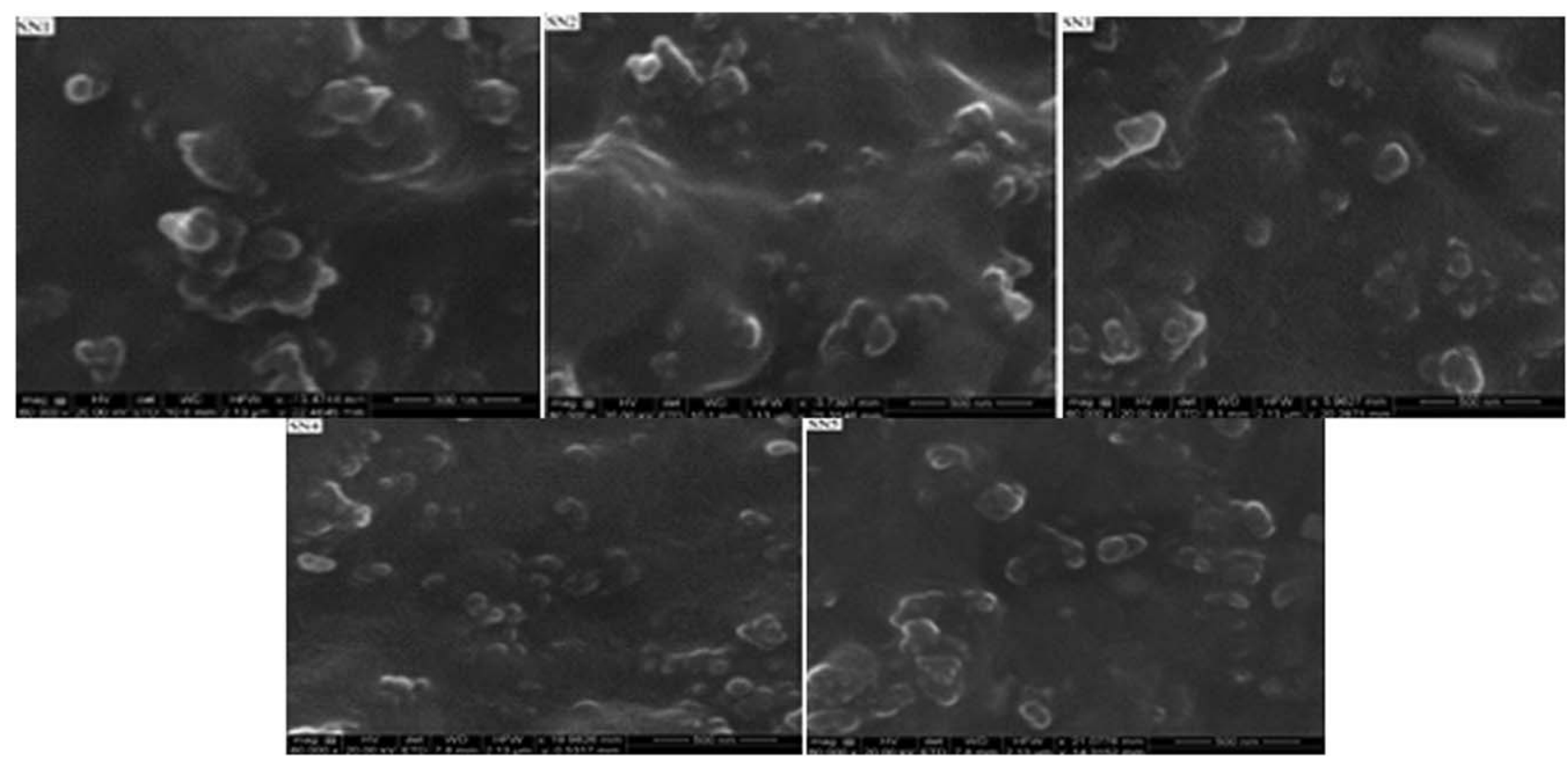

FIG. 15. SEM photomicrographs of SN1, SN2, SN3, SN4, and SN5 sample code. 
The optical microscopic images revealed the uniform and finer dispersion of filler in the continuous rubber matrix phase.

\section{Morphological Behavior}

The SEM images of NBR/SBR nanocomposites were shown in Fig. 15a-e. The morphology of these nanocomposites were examined using SEM. SEM image of NBR/ SBR blend indicates two-phase morphology (Fig. 15a). This is because of carbon black acts as dispersed phase and blend acts as continuous phase. Figure $15 \mathrm{~b}$ indicates SEM photograph of CSP-loaded composites. It is also exhibiting two-phase morphology and CSP powder completely embedded in the elastomeric phase. Nanoclay loaded systems are also showed two phase morphology. The SEM images of all nanocomposites indicate the smooth surface. All the SEM pictures indicate the homogeneous and finer dispersion of co-fillers (CSP and nanoclay) in continuous elastomeric phase. Furthermore, the incorporation of the filler improved the compatibility between the NBR and SBR, resulting in almost a homogeneous phase.

\section{CONCLUSIONS}

Crysnanoclay was used as a reinforcing filler at varying amounts in NBR/SBR (50/50) blend. The role of the filler was investigated using physico-mechanical properties, thermal properties and SEM. From the tensile behavior it was observed that the incorporation of CSP component into blend matrix improves the surface hardness and tensile modulus of the resulting systems significantly. TGA analysis revealed that, all nanocomposite exhibits two steps thermal degradation processes and there was a slight reduction in the thermal stability of the composites after incorporation of CSP into rubber matrix. Two steps thermal degradation is because of TGA scans recorded in nitrogen media.

The water uptake values of the nanocomposites decreases significantly with increase in nanoclay content. This result clearly indicates that the water uptake behavior of the composites significantly depends on the filler content. Solvent resistance of the samples increased upon the addition of nanostructured silicates because of the intercalation of rubber chain into the layers. It will result in nanometric level of dispersion of silicates into the rubber matrix. It was observed that as the size of the probe molecules increased, the solvent uptake of polymer decreased in the order; benzene $>$ toluene $>p$-xylene.
SEM photomicrographs indicates homogenous and finer dispersion of CSP and CN co-fillers in rubber matrix.

CSP could be utilized as biodegradable filler to minimize environmental pollution rather than strong reinforcing filler for polymeric materials.

\section{REFERENCES}

1. W. Chow, Z.A. Ishak, U.S. Ishiaku, J. Karger-Kocsis, and A.A. Apostolov, J. Appl. Polym. Sci., 91, 175 (2004).

2. H. Farzana and H. Mehdi, J. Compos. Mater., 40, 1511 (2006).

3. A. Zulfiqar, L. Hai Hong, I. Sybill, T.-A. Thomas, and R. Hans-Joachim, Polymer, 51, 4580 (2010).

4. M.Y. Gelfer, H.S. Hyun, L. Lizhi, S.H. Benjamin, C. Benjamin, R. Miriam, S. Mayu, and Z. Vladimir, J. Polym. Sci. Part B: Polym. Phys., 41, 44 (2003).

5. M. Yong, W. You-Ping, Z. Li-Qun, and L. Qi-Fang, J. Appl. Polym. Sci., 109, 1925 (2008).

6. N. Takeo, O. Anri and M. Akikazu, J. Appl. Polym. Sci., 120, 434 (2011).

7. ASTM D 395. Standard test method for rubber propertycompression set of vulcanized rubber. Philadelphia: Annual Book of ASTM Standards; 1955.

8. B. Susheela, D.V. Khakhar, and M. Nadkarni, Polymer, 38, 4319 (1997).

9. Siddaramaiah, P. Mallu, S. Roopa, H. Somashekarappa, and R. Somashekar, J. Appl. Polym. Sci., 95, 764 (2005).

10. L.P. Smith, Ed., The Language of Rubber, Butterworth Heinemann, London (1993).

11. A.B. Othman, Polym. Test., 20, 159 (2001).

12. L. Zhu and R.P. Wool, Polym. Sci., 47, 8106 (2006).

13. W.S. Chow, A. Abu Bakar, and Z.A. Mohd Ishak, J. Appl. Polym. Sci., 98, 780 (2005).

14. G.G. Konstantinos, S. László, P. Béla, and K.-K. József, Macromol. Rapid Commun., 26, 915 (2005).

15. T. Hatkeyama and F.X. Quinn, Thermal Analysis, Fundamentals and Applications to Polymer Science, Wiley, Cichester (1994).

16. S. Pashaei, Siddaramaiah, and A.A. Syed, J. Macromol. Sci. A Chem., 47, 777 (2010).

17. T. Jeevananda and Siddaramaiah, Thermochem. Acta, 376, 51 (2001).

18. H. Kumar, A. Anilkumar, and Siddaramaiah, Polym. Degrad. Stab., 91, 1097 (2006).

19. P. Shahryar, Siddaramaiah, and A.A. Syed, Polym. Plast. Technol. Eng., 50, 973 (2011).

20. K. Annakuttya and K. Kishorea, Eur. Polym. J.,29, 1387 (1993).

21. B.R. Richmond, Rubber Division, Orlando, Florida 158, (1993). 